DOI: 10.32743/UniTech.2021.85.4-3.48-50

\title{
АНАЛИЗ СОСТАВА ПЛОДОВ БОЯРЫШНИКА И ПРОЦЕССА ИХ СУШКИ
}

\author{
Рахманова Тожинисо Турсунбой кизи \\ соискатель, \\ Ташкентский государственный технический университет, \\ Республика Узбекистан, г. Ташкент \\ E-mail: tojinisoraxmanova07@gmail.com
}

Tojiniso Rakhmanova

Applicant,

Tashkent State Technical University, Uzbekistan, Tashkent

\begin{abstract}
АННОТАЦИЯ
В этой статье представлена информация о плодах боярышника красного и содержащихся в нем витаминах. При этом результаты сушки плодов боярышника красного конвективным способом отражаются в виде таблиц и кривых. В проведенной исследовательской работе был проведен процесс сушки плодов боярышника красного бланшированием в простой воде и растворе лимонной кислоты.
\end{abstract}

ABSTRACT

This article provides information about the fruits of red hawthorn and the vitamins contained in it. At the same time, the results of drying red hawthorn fruits by convective method are reflected in the form of tables and curves. In the conducted research work, the process of drying the fruits of red hawthorn was carried out by blanching in plain water and a solution of citric acid.

Ключевые слова: конвективная сушка, бланширование, антиоксиданты, плоды боярошника, фенолные, предварительная обработка, витамин С.

Keywords: convective drying, blanching, antioxidants, drying, crataegi fructus, phenolics, pretreatment, vitamin C.

Боярышник (Боярышник) - кустарник или дерево до 5 метров высотой, относящееся к семейству боярышниковых. Растет в горах, кустарниках и лугах. В медицине используются следующие шесть видов фруктов и цветов:

- Боярышник алтайский (Боярышник желтый) - (Боярышник алтайский)

- Боярышник даурский - (Боярышник даурский)

- Боярышник темно-красный - (Бояришник кроваво-красный)

- Боярышник терновник - (Боярышник колючий)

- Боярышник одинокий семенной - (Боярышник однопестичный)

- Боярышник пятисеместный - (Боярышник пятипестичный)

Плоды боярышника содержат сапонины тритерпеновые, кислоты, флавоноиды (гиперозид, кверцетрин, кверцетин и др.), холин, добавки, в цветке - лавоноиды, эфирное масло, тритерпеновые сапонины, холин, ацетилхолин и другие соединения. Лекарства (настой цветка (настойка) и жидкий экстракт плодов) сердце при лечении пчелиных укусов, гипертонии и др. использовал. Жидкий экстракт плодов входит в состав препарата кардиовален, который применяется при сердечных заболеваниях.

В процессе обезвоживания из ячеек продукта, как правило, выделяется только физико-химическая и механически связанная вода. Легче всего испаряется механически скопившаяся влага. Она делится на влагу в макро и микрокапиллярах. После высыхания сначала испаряется влага из крупных капилляров. Влага в капиллярах, удерживаемая за счет адсорбционной силы, испаряется с трудом. Капиллярная влага выделяется как в жидкой, так и в парообразной форме. Их называют свободной влагой, испарение которой подчиняется закону испарения жидкости с открытой поверхности [2-5].

Основные параметры режима сушки - это температура воздуха, скорость воздуха и влажность. Они влияют как на характер операции процесса, так и на свойства материала, подлежащего сушке. Повышение температуры воздуха увеличивает скорость сушки, которая, по мнению некоторых авторов, приводит к увеличению коэффициента теплопередачи между телом и влажным воздухом. Однако повышение температуры, как правило, ограничивает термо чувствительность большинства трав, фруктов и овощей и приводит к увеличению коэффициента теплопередачи между телом и влажным воздухом. Высокие температуры могут привести к необратимым изменениям в компонентах коллоидной ткани, а также к повышению потерь тепла и снижает эффективность всей системы [1].

Конвективная сушка - при которой сушильный проводник непосредственно взаимодействует с влажным материалом [7]. Обычно в качестве проводника сушки используют нагретый воздух или дымовые газы [6].

Библиографическое описание: Рахмонова Т.Т. Анализ состава плодов боярышника и процесса их сушки // Universum: технические науки : электрон. научн. журн. 2021. 4(85). URL: https://7universum.com/ru/tech/archive/item/11495 (дата обращения: 25.04.2021). 
Проведенные исследовательские работы проводились на установке гелионагревателе.

В ходе исследования были выбраны две различные среды для сушки ягод боярышника красного: простая вода при $65{ }^{\circ} \mathrm{C}$ и $1,5 \%$ раствор лимонной кислоты при $65^{\circ} \mathrm{C}$. Мы обсудим эти процессы сушки ниже.

В процессе бланширования и сушки в обычной воде плоды боярышника промывали и очищали, бланшировали в воде при температуре $65^{\circ} \mathrm{C}$ до 15 минут и сушили в гелионагревателе. Результаты сушки следующие:

Таблицุа 1.

Результат процесса сушки бланшированных плодов боярошника в воде с температурой $65^{\circ} \mathrm{C}$

\begin{tabular}{|c|c|}
\hline Масса, гр & Влажность, $\%$ \\
\hline 728 & 20,14 \\
\hline 701 & 19,4 \\
\hline 682 & 18,87 \\
\hline 660 & 18,26 \\
\hline 645 & 17,85 \\
\hline 630 & 17,43 \\
\hline 616 & 17,04 \\
\hline 602 & 16,66 \\
\hline 589 & 16,3 \\
\hline 582 & 16,1 \\
\hline 578 & 15,99 \\
\hline 563 & 15,58 \\
\hline 554 & 15,33 \\
\hline 542 & 15 \\
\hline
\end{tabular}

В процессе бланширования в 1,5\% растворе лимонной кислоты ягоды боярышника бланшировали до 15 минут после промывки. Температура воды была $65{ }^{\circ} \mathrm{C}$. Бланшированные ягоды боярышника сушили в гелионагревателе. Результаты сушки следующие:

Таблица 2.

Результат процесса сушки бланшированных плодов боярошника в растворе лимонной кислоты 1,5\%

\begin{tabular}{|c|c|}
\hline Масса, гр & Влажность, $\%$ \\
\hline 723 & 23,62 \\
\hline 692 & 22,61 \\
\hline 681 & 22,25 \\
\hline 663 & 21,66 \\
\hline 651 & 21,27 \\
\hline 638 & 20,84 \\
\hline 574 & 18,75 \\
\hline 554 & 18,1 \\
\hline 536 & 17,51 \\
\hline 515 & 16,83 \\
\hline 496 & 16,2 \\
\hline 459 & 15 \\
\hline
\end{tabular}

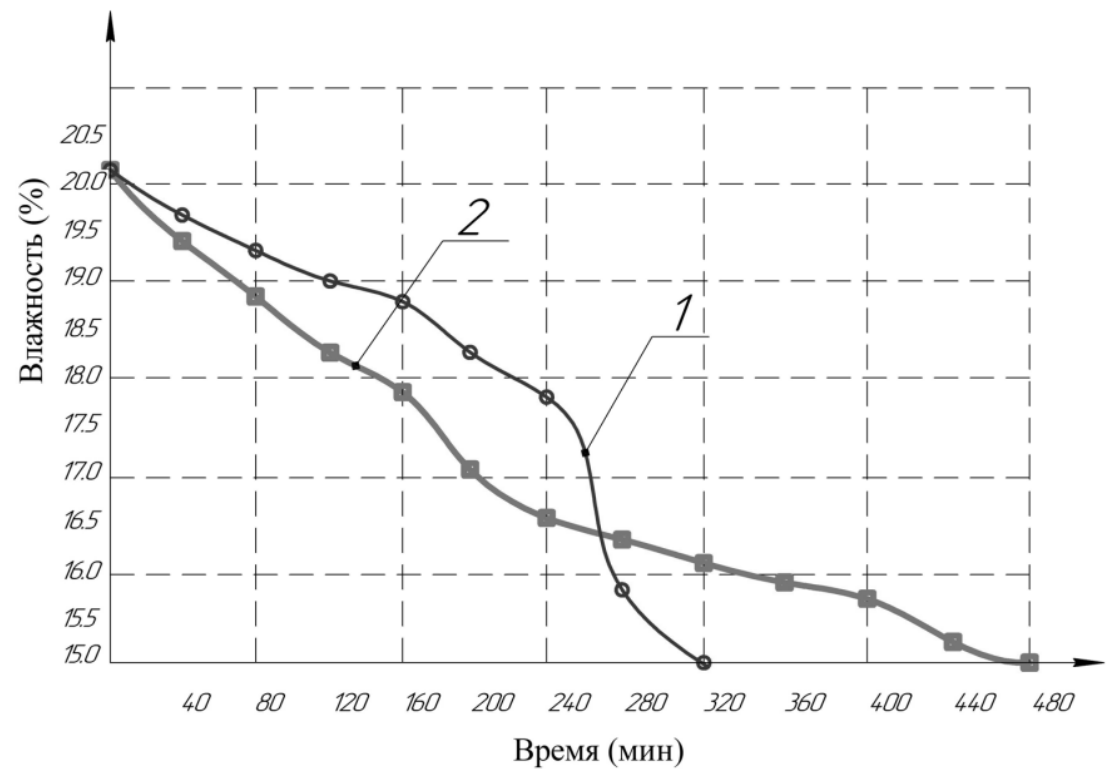

1 - Бланширован в 1,5\% растворе лимонной кислоты; 2 - Бланшированный боярошник в воде с температурой $65^{\circ} \mathrm{C}$.

Рисунок 1. Кривая процесса сушки плодов боярошника 


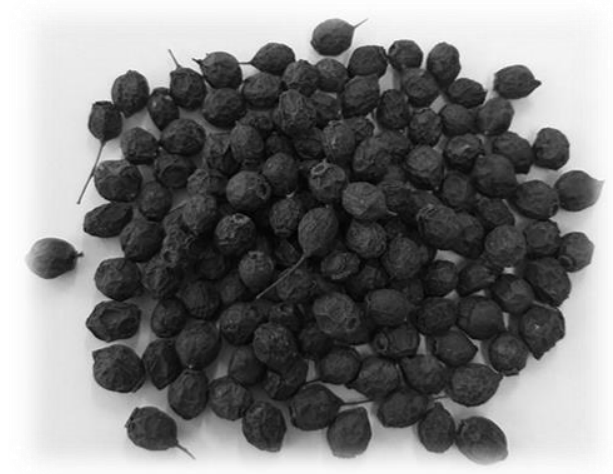

1 - Бланширован в 1,5\% растворе лимонной кислоты

Вывод. Бланширование сушеного боярошника 1,5 мин в растворе лимонной кислоты при 320 мин, бланширование сушеного боярошника в обычной воде при температуре $65^{\circ} \mathrm{C}$, бланширование сушеного

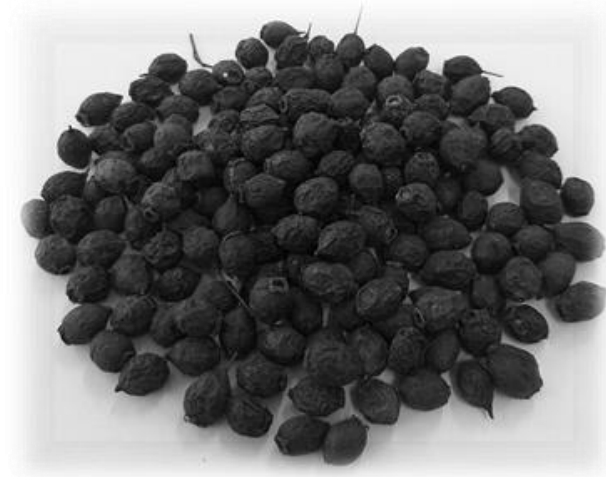

2 - Бланшированный боярочник в воде с температурой $65^{\circ} \mathrm{C}$.

боярошника 480 мин. Видно, что бланширование в растворе лимонной кислоты требует меньше времени и достигается качественная сушка.

\section{Список литературы:}

1. A.A. Alsaffar, "Sustainable diets: The interaction between food industry, nutrition, health and the environment," Food Science and Technology International, vol. 22, no. 2, 2016, pp. 102-111.

2. L. Rashidi and K. Khosravi-Darani, "The applications of nanotechnology in food industry, Critical Reviews in Food Science and Nutrition, vol. 51, no. 8, 2011, pp. 723730.

3. Sultanova Sh.A., Safarov J.E. Experimental study of the drying process of medicinal plants. // International Journal of Psychosocial Rehabilitation (Scopus). Volume 24, Issue 8. 2020. P.1962-1968. DOI: 10.37200/IJPR/V24I8/PR280216

4. Сафаров Ж.Э., Султанова Ш.А., Дадаев Г.Т. Разработка гелиосушильной установки на основе теоретических исследований аккумуляции тепловой энергии.//Эергетика. Известия высших учебных заведений и энергетических объединений СНГ (Scopus). Т.63, №2 (2020), с. 174-192.

5. Сафаров Ж.Э., Султанова Ш.А., Beraat Özçelik, Gürbüz Güneş. Программное обеспечение математической модели технологии качественной переработки лечебных растений. DGU 07724 от 12.02.2020 г.

6. Sultanova Sh.A., Safarov J.E., Raxmanova T.T. Drying medicinal plants with the storage of antioxidant properties. International Journal of Advanced Science and Technology. Volume 29, №9s. 2020. pp.2115-2119.

7. Sultanova Sh.A., Safarov J.E., Usenov A.B., Raxmanova T.T. Definitions of useful energy and temperature at the outlet of solar collectors. E3S Web of Conferences 216, 01094 (2020) RSES 2020, https://doi.org/10.1051/e3sconf/202021601094. 